\title{
Low-temperature magnetic properties of andesitic rocks from Popocatepetl stratovolcano, Mexico
}

\author{
Andrei Kosterov $^{1}$, Gennaro Conte ${ }^{2}$, Avto Goguitchaichvili ${ }^{3,4}$, and Jaime Urrutia-Fucugauchi ${ }^{2}$ \\ ${ }^{1}$ Center for Advanced Marine Core Research, Kochi University, B200 Monobe, Nankoku, Kochi 783-8502, Japan \\ ${ }^{2}$ Instituto de Geofisica, Universidad Nacional Autonoma de México, Ciudad Universitaria S/N, 04510 Mexico D.F., Mexico \\ ${ }^{3}$ Laboratorio Interinstitucional de Magnetismo Natural, Instituto de Geofisica, Sede Michoacan, Universidad Nacional Autonoma de Mexico, \\ Campus Morelia, Tzintzuntzan 310, Vista Bella, 58098 Morelia, Michoacan, Mexico \\ ${ }^{4}$ Departamento de Geologia y Mineralogia, Instituto de Investigaciones Metalurgicas, Universidad Michoacana de San Nicolas de Hidalgo
}

(Received October 3, 2007; Revised March 14, 2008; Accepted March 27, 2008; Online published January 23, 2009)

\begin{abstract}
To contribute to the growing database of magnetic properties of rocks and minerals at cryogenic temperatures, we have measured magnetization, low-field susceptibility, and hysteresis loops as a function of temperature between $2 \mathrm{~K}$ (10 K for hysteresis) and $300 \mathrm{~K}$ for twelve representative samples from a suite of volcanic rocks of predominantly andesitic composition erupted by the Popocatepetl stratovolcano, Mexico. High temperature susceptibility measurements have yielded Curie points $\left(T_{\mathrm{C}}\right)$ mostly between 430 and $550^{\circ} \mathrm{C}$, two samples additionally containing a magnetic phase with $T_{\mathrm{C}}$ of $300-320^{\circ} \mathrm{C}$, and one sample-with $140-170^{\circ} \mathrm{C}$. Hysteresis measurements at room temperature have revealed invariably the presence of a low-coercivity mineral with coercive force ranging from 10 to $20 \mathrm{mT}$. This suggests that NRM of Popocatepetl rocks is carried by an intermediate titanomagnetite of composition between approximately TM04 and TM20. Thermal demagnetization of SIRM given at $2 \mathrm{~K}$ displays no evidence for the Verwey transition, further showing that samples are essentially magnetite free. At the same time, an inflection between $30-50 \mathrm{~K}$ reported previously for intermediate titanomagnetites (Moskowitz et al., EPSL, 157, 141-149, 1998) is seen in all studied Popocatepetl samples except one. As well, below $50 \mathrm{~K}$ the coercive force increases sharply with decreasing temperature reaching up to $100 \mathrm{mT}$ at $10 \mathrm{~K}$. On the other hand, examining the behavior of low-field susceptibility at cryogenic temperatures shows that susceptibility signal is dominated by intermediate titanomagnetites only in a part of our samples. In four out of 12 samples, however, susceptibility signal appears to be due to a hemoilmenite phase containing about 20 mole $\%$ of hematite. Caution is thus advised when interpreting low-temperature susceptibility data in terms of magnetic mineralogy.
\end{abstract}

Key words: Titanomagnetite, hemoilmenite, low-temperature magnetic properties, andesites.

\section{Introduction}

Recent years have seen a renewed interest in the magnetic properties of rocks and minerals at cryogenic temperatures, stimulated by growing availability of commercial instruments capable to carry out magnetic measurements down to and below $4.2 \mathrm{~K}$. However, by far the greatest attention has been paid to studies of pure minerals (Kosterov, 2007 and references therein). Of natural materials, the preferred target for low-temperature magnetic measurements are sediments and sedimentary rocks, and also soils and loess. This preference is a consequence of limited applicability of traditional high-temperature magnetic techniques in studies of the magnetic mineralogy of sediments, because of chemical alteration during heating. At the same time, relatively little has been reported on the magnetic properties of volcanic rocks at low temperatures and, moreover, these studies have been so far limited to basalts (Radhakrishnamurty et al., 1981; Senanayake and McElhinny, 1981, 1982; UrrutiaFucugauchi et al., 1984; Thomas, 1993; Shau et al., 2000; Kosterov, 2001; Kontny et al., 2003; Yamamoto, 2006).

Copyright (c) The Society of Geomagnetism and Earth, Planetary and Space Sciences (SGEPSS); The Seismological Society of Japan; The Volcanological Society of Japan; The Geodetic Society of Japan; The Japanese Society for Planetary Sciences; TERRAPUB.
In order to extend the existing data to other types of volcanic rocks, we present here results of the study of the low-temperature magnetic properties of andesites from the Popocatepetl stratovolcano in central Mexico.

\section{Samples}

Samples come from different lava flows from Popocatepetl, which is a dacitic-andesitic stratovolcano located in the central-eastern sector of the Trans-Mexican volcanic belt (TMVB, Fig. 1(a)). The volcanic belt includes several volcanoes developed within a region characterized by intense Plio-Quaternary magmatic and tectonic activity, which is manifested in extensive monogenetic cinder cone fields and tall, composite dacitic-andesitic stratovolcanoes.

Lava flows studied mostly correspond to andesites and some trachyandesites (Fig. 1(b)). Samples, rich in plagioclase, pyroxene and olivine, are calc-alkaline and magnesian andesites, with similar major-oxide and trace-element compositions: 57-63\% $\mathrm{SiO}_{2},>6 \% \mathrm{MgO}$, low $\mathrm{CaO}, \mathrm{Al}_{2} \mathrm{O}_{3}$, and $\mathrm{FeO}$, and high $\mathrm{Na}_{2} \mathrm{O}$. A characteristic feature is presence of magnesian, $\mathrm{Cr}$-spinel fosteritic olivine, which has been taken as evidence of magma mixing with a mafic component still recognizable (Conte et al., 2004).

Observations on thin polished sections (Fig. 1(c)) show in 

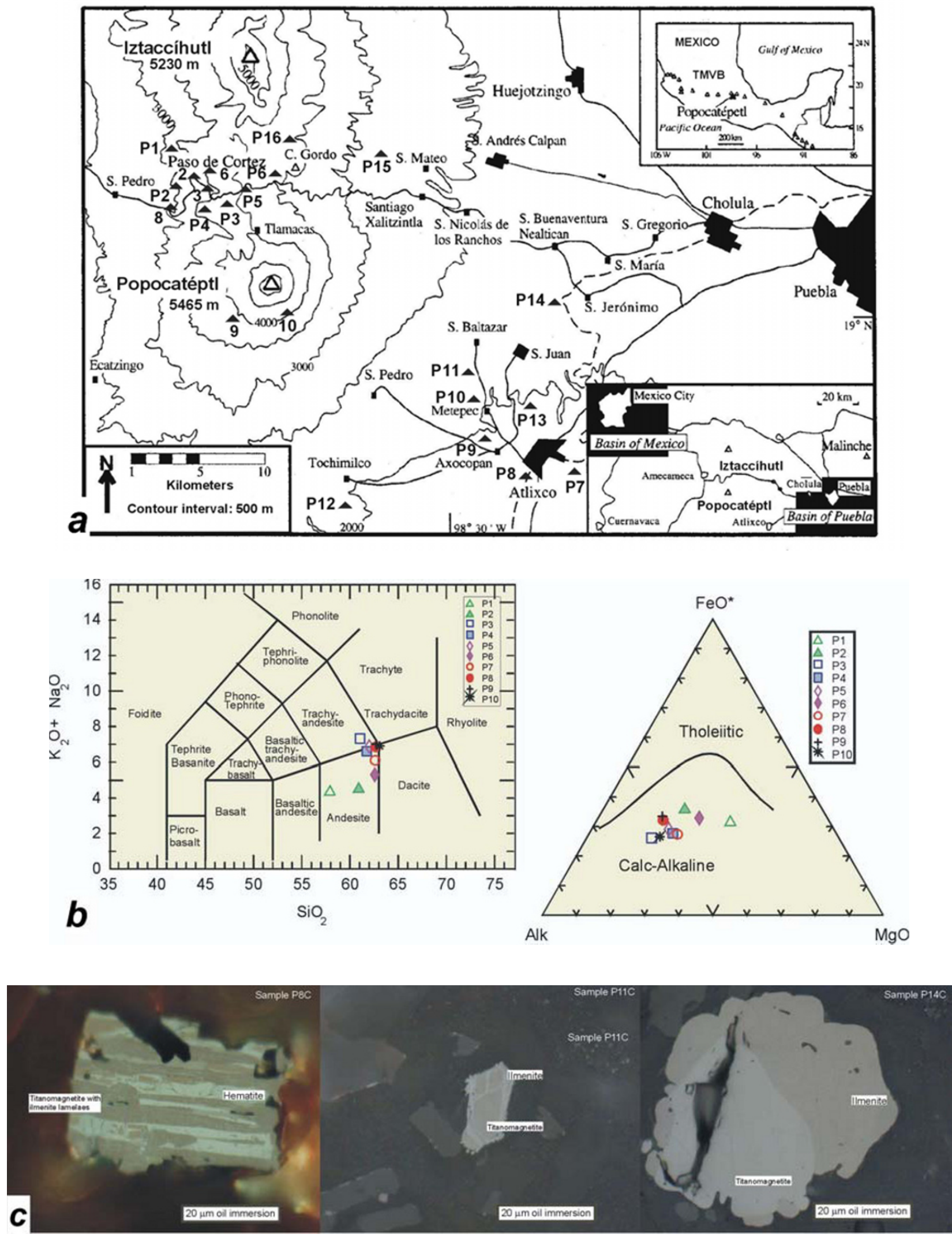

Fig. 1. (a) Location of sampling sites (filled triangles) in the Popocatepetl stratovolcano, eastern sector of the Trans Mexican Volcanic Belt (adapted from Conte et al., 2004). (b) Geochemical characteristics: Left panel shows $\mathrm{Na}_{2} \mathrm{O}+\mathrm{K}_{2} \mathrm{O}$ (wt\%) as a function of $\mathrm{SiO}_{2}$ (major-oxide data from Carrasco-Nuñez et al., 1986; Conte et al., 2004). Studied units are classified mostly as andesites and some as trachyandesites in the silica versus total alkalies classification system for volcanic rocks. Right panel shows major-oxide chemical data for Popocatepetl units plotted in an AFM (alkalies-FeO-MgO) ternary diagram. (c) Reflected light microphotographs of representative samples from Popocatepetl, oil immersion, crossed nicols. 
Table 1. Summary of rock magnetic properties.

\begin{tabular}{|c|c|c|c|c|c|c|c|c|c|}
\hline \multirow{2}{*}{ Sample } & \multirow{2}{*}{$T_{\mathrm{C}},{ }^{\circ} \mathrm{C}$} & \multicolumn{4}{|c|}{ Hysteresis at $300 \mathrm{~K}$} & \multirow{2}{*}{$\begin{array}{c}H_{\mathrm{c}}, 10 \mathrm{~K}, \\
\pm 1 \mathrm{~T} \text { loops, } \mathrm{mT}\end{array}$} & \multirow{2}{*}{ SIRM memory } & \multicolumn{2}{|c|}{ Grouping according to: } \\
\hline & & $M_{\mathrm{rs}} / M_{\mathrm{s}}$ & $H_{\mathrm{c}}, \mathrm{mT}$ & $H_{\mathrm{cr}}, \mathrm{mT}$ & $H_{\mathrm{cr}} / H_{\mathrm{c}}$ & & & RT-SIRM cycle & $\chi(\mathrm{T})$ \\
\hline p01 & 520 & 0.180 & 17.88 & 36.42 & 2.037 & 62.32 & 0.751 & $\mathrm{I}$ & I \\
\hline p02 & 545 & 0.128 & 11.11 & 26.93 & 2.424 & 56.73 & 0.751 & I & I \\
\hline p04 & $430 ; 460$ & 0.112 & 10.33 & 26.59 & 2.574 & 95.49 & 0.796 & I & I \\
\hline p08 & $430 ; 485$ & 0.126 & 11.37 & 36.71 & 3.229 & 37.92 & 0.689 & I & I \\
\hline p09 & 520 & 0.177 & 12.19 & 25.47 & 2.089 & 94.15 & 0.892 & II & $\mathrm{I}+\mathrm{II}$ \\
\hline p10 & $160 ; 440 ; 520$ & 0.378 & 39.38 & 85.87 & 2.181 & 52.44 & 0.943 & II & II \\
\hline p11 & $300 ; 525(?) ; 570$ & 0.388 & 39.83 & 90.90 & 2.282 & 44.72 & 0.916 & II & II \\
\hline p12 & $315 ; 490$ & 0.333 & 18.67 & 31.06 & 1.664 & 73.10 & 0.941 & II & II \\
\hline p13 & 505 & 0.186 & 16.27 & 36.75 & 2.259 & 36.14 & 0.879 & $\mathrm{I}+\mathrm{II}$ & $\mathrm{I}+\mathrm{II}$ \\
\hline p14 & 500 & 0.363 & 39.84 & 88.16 & 2.213 & 93.65 & 0.903 & II & $\mathrm{I}+\mathrm{II}$ \\
\hline p15 & 535 & 0.284 & 24.21 & 104.30 & 4.308 & 55.50 & 0.966 & II & II \\
\hline p16 & 520 & 0.193 & 18.21 & 40.60 & 2.230 & 74.06 & 0.845 & $\mathrm{I}+\mathrm{II}$ & II \\
\hline
\end{tabular}
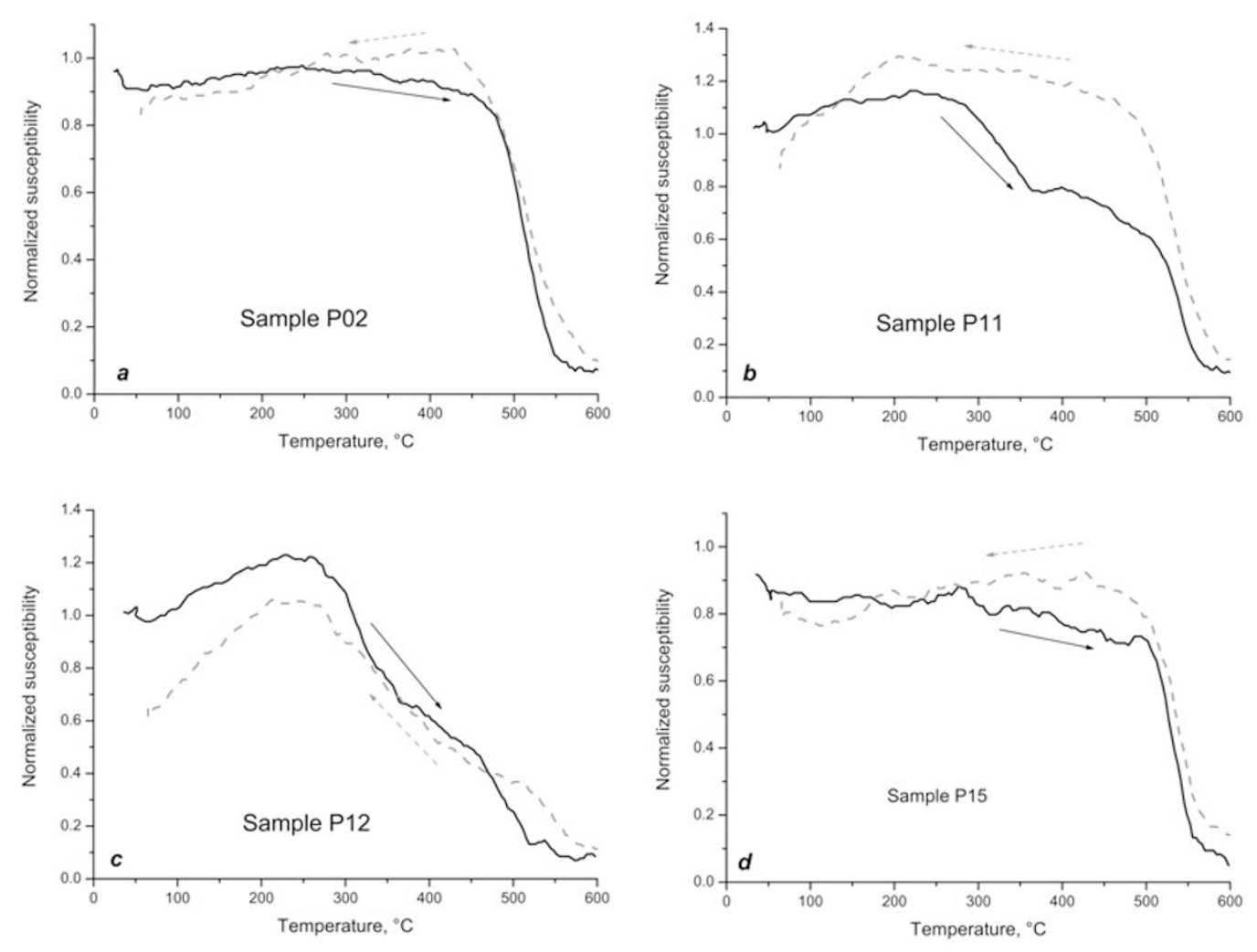

Fig. 2. Examples of high-temperature $k-T$ curves. Heating and cooling curves are shown by arrows.

most cases the titanomagnetite intergrowth with the lamellar ilmenite (sample P14, Ti-poor titanomagnetite associated with ilmenite exsolution of trellis type). This corresponds to high degree of oxy-exsolution, since optically more reflective hematite is also detected. We note in passing that no compelling evidence for hematite can be found in magnetic data. In other cases (samples P8 and P11), titanium-poor titanomagnetites are associated with large lamellae of ilmenite (sandwich form?). This paragenesis commonly occurs at high temperatures and suggests that the remanence is thermoremenent magnetization.

Twelve samples (one per site) have been selected for the present study from a collection sampled for a combined paleomagnetic and geochemical study (Conte et al., 2004). For all these sites, thermal demagnetization has successfully isolated a characteristic remanent magnetization (ChRM) component with maximum unblocking temperatures in the $500-550^{\circ} \mathrm{C}$ range. Fourteen samples from four different sites yielded technically acceptable paleointensity estimates with the Thellier method, implying the primary TRM origin of the characteristic remanence.

Magnetic mineralogy has first been assessed using standard thermomagnetic analyses and hysteresis measurements at room temperature. Low-field susceptibility has been measured as a function of temperature in air using a Bartington susceptibility meter connected with a furnace. 

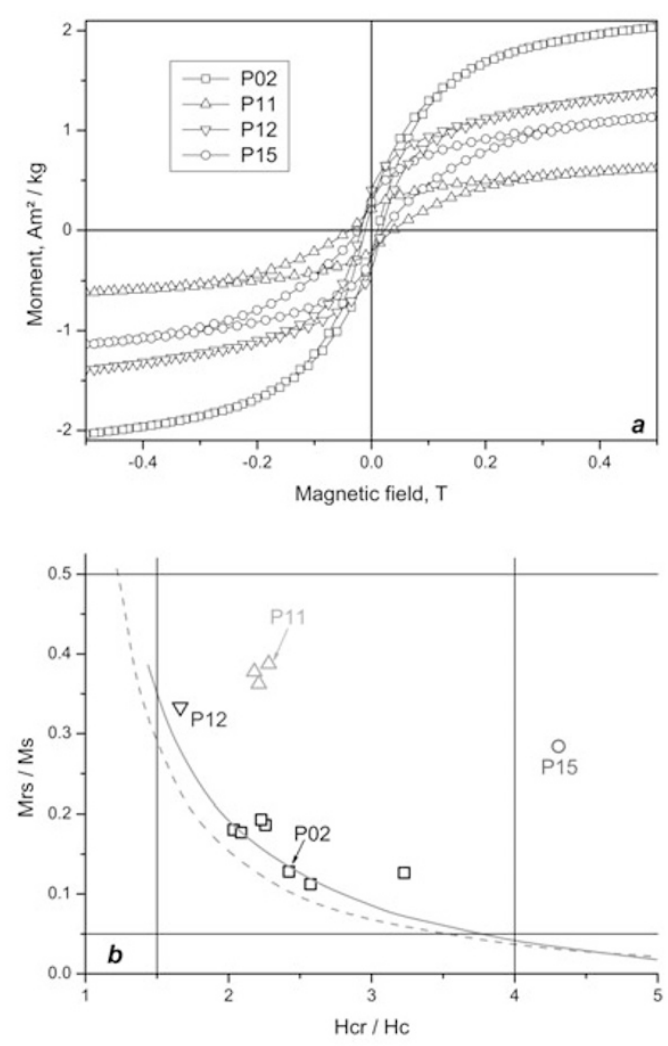

Fig. 3. Examples of room temperature hysteresis loops (a) and the respective Day plot (b). Solid and dash lines in the Day plot show two SD-MD mixing trends after Dunlop (2002).

Curie temperatures were determined as a minimum in the derivative of a heating branch of a $k-T$ curve. However, only features replicated during cooling were analyzed. Hysteresis loops and backfield curves at room temperature have been measured with a Princeton Measurements vibrating sample magnetometer (VSM) in a maximum field of $1 \mathrm{~T}$.

Results of these experiments can be summarized as follows (Table 1). All samples appear to contain one or, in some cases, two magnetic phases with relatively high Curie temperatures ranging from 430 to $550^{\circ} \mathrm{C}$ (Fig. 2). Two samples, $\mathrm{P} 11$ and $\mathrm{P} 12$, contain an additional phase with $T_{\mathrm{c}}$ about $300-320^{\circ} \mathrm{C}$, and sample $\mathrm{P} 10$ shows a Curie point in the $140-170^{\circ} \mathrm{C}$ range. For eight out of twelve samples $M_{\mathrm{rs}} / M_{\mathrm{s}}$ versus $H_{\mathrm{cr}} / H_{\mathrm{c}}$ ratios follow the SD-MD trend for low-Ti titanomagnetites (Dunlop, 2002), falling into the pseudo single domain (PSD) area in the Day plot (Fig. 3(b)). Four others, while still in the PSD area, plot outside this trend, the most extreme case being represented by sample P15 which shows a wasp-waisted hysteresis loop with relatively high $M_{\mathrm{rs}} / M_{\mathrm{s}}$ and $H_{\mathrm{cr}} / H_{\mathrm{c}}$ ratios (0.284 and 4.3 , respectively).

\section{Low-temperature Experiments \\ 3.1 Experimental procedures}

Measurements of Saturation Isothermal Remanent Magnetization (SIRM) and of the AC complex susceptibility as a function of low temperature were carried out with an MPMS XL instrument at National Institute of Advanced Industrial Science and Technology (AIST), Tsukuba. Ther- mal demagnetization of SIRM given in a $5 \mathrm{~T}$ field at $2 \mathrm{~K}$ (LT-SIRM, for short) was measured twice, first after cooling in zero magnetic field (ZFC), and then after cooling in a $5 \mathrm{~T}$ field (FC). Also, evolution of SIRM given in the same field at $300 \mathrm{~K}$ (RT-SIRM) has been traced during a 300-6$300 \mathrm{~K}$ cycle in zero field. Temperature dependence of the AC susceptibility $\chi=\chi^{\prime}-i \chi^{\prime \prime}$ has been measured from $2 \mathrm{~K}$ to room temperature also with the MPMS XL instrument in Tsukuba. For six out of twelve samples susceptibility vs. temperature curves have been measured in the AC field of $100 \mu \mathrm{T}$ amplitude at three driving frequencies, 8, 80, and $800 \mathrm{~Hz}$. For the rest six samples, a single curve at $10 \mathrm{~Hz}$ frequency has been measured.

Hysteresis measurements at low temperatures were performed using a Princeton Measurements VSM equipped with a liquid He cryostat at Tokyo Institute of Technology. Maximal field of the hysteresis loop was $1 \mathrm{~T}$, and magnetic field increment $5 \mathrm{mT}$. Hysteresis loops were measured on warming after an initial cooling to $10 \mathrm{~K}$ in zero magnetic field (ZFC) started from DC-demagnetized state, and also after cooling in a $0.7 \mathrm{~T}$ field (field-cooling, FC). In the latter experiments, hysteresis loops were measured in the direction of a magnetic field applied during cooling. For most samples, temperature increments used were $5^{\circ}$ in the 10 $100 \mathrm{~K}$ range and $20^{\circ}$ above $100 \mathrm{~K}$. Usually, a target temperature could be established and kept constant to within $1^{\circ}$ during three to five minutes required to trace a complete loop. Additionally, hysteresis loops at 10 and $50 \mathrm{~K}$ after ZFC were measured for two selected samples in a $5 \mathrm{~T}$ maximum field using an MPMS XL instrument.

\subsection{LT- and RT-SIRM variation as a function of tem- perature}

Examples of LT-SIRM warming curves are given in Fig. 4. At the first glance, no indication of the Verwey transition, characteristic of magnetite, is evident. A more detailed inspection of SIRM derivative curves in conjunction with the hysteresis vs. temperature data (see Section 3.4 below) revealed only a very weak indication of the Verwey transition in the sample P13. Other samples do not show the Verwey transition whatsoever and therefore should be essentially magnetite-free, in agreement with high-temperature susceptibility data.

The overall shape of LT-SIRM warming curves is quite variable. Two types of behaviour can be recognized. The first one (Fig. 4(a), (b)), observed in eight out of twelve samples, is characterized by a break-in-slope occurring somewhere between 15 and $50 \mathrm{~K}$. It may be further noted that the lower the break-in-slope temperature the steeper the initial and the shallower the final slope. The second type (Fig. 4(c)) is characterized by an almost featureless SIRM(T) curve with the slope gently decreasing with the increased temperature. This type of behavior is seen in the pure form only in sample P16. Samples P01, P02, and P08 (Fig. 4(d)) apparently show a mix of the two above types of behavior.

LT-SIRM warming curves measured after ZFC and FC, respectively, somewhat differ. $\mathrm{FC} \operatorname{SIRM}(2 \mathrm{~K})$ typically exceeds that measured after ZFC by $10-30 \%$. For some samples, the difference between FC and ZFC LT-SIRM curves disappears at the break-in-slope feature. For the 

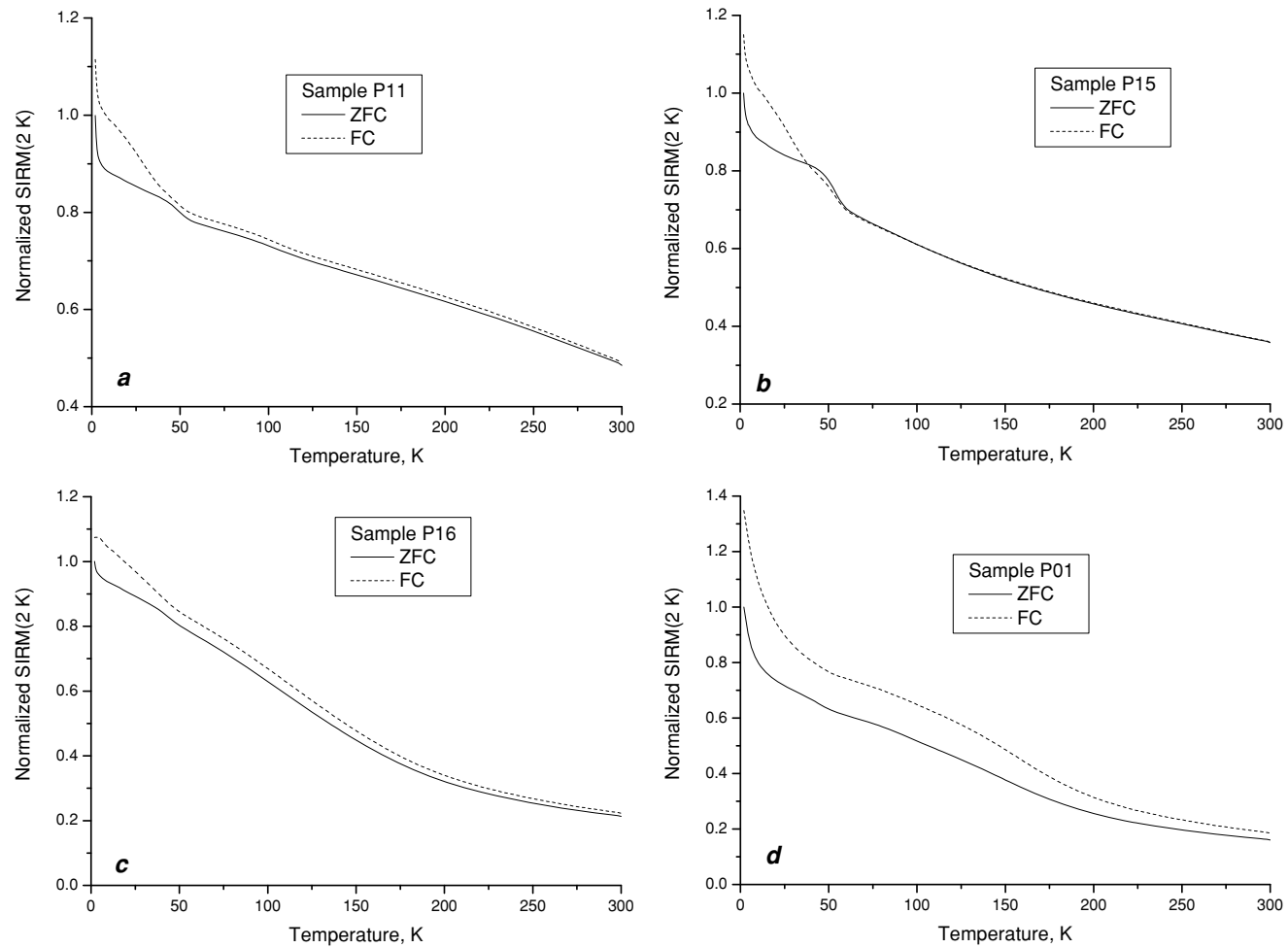

Fig. 4. Thermal demagnetization of SIRM acquired at $2 \mathrm{~K}$ after ZFC and FC treatments.
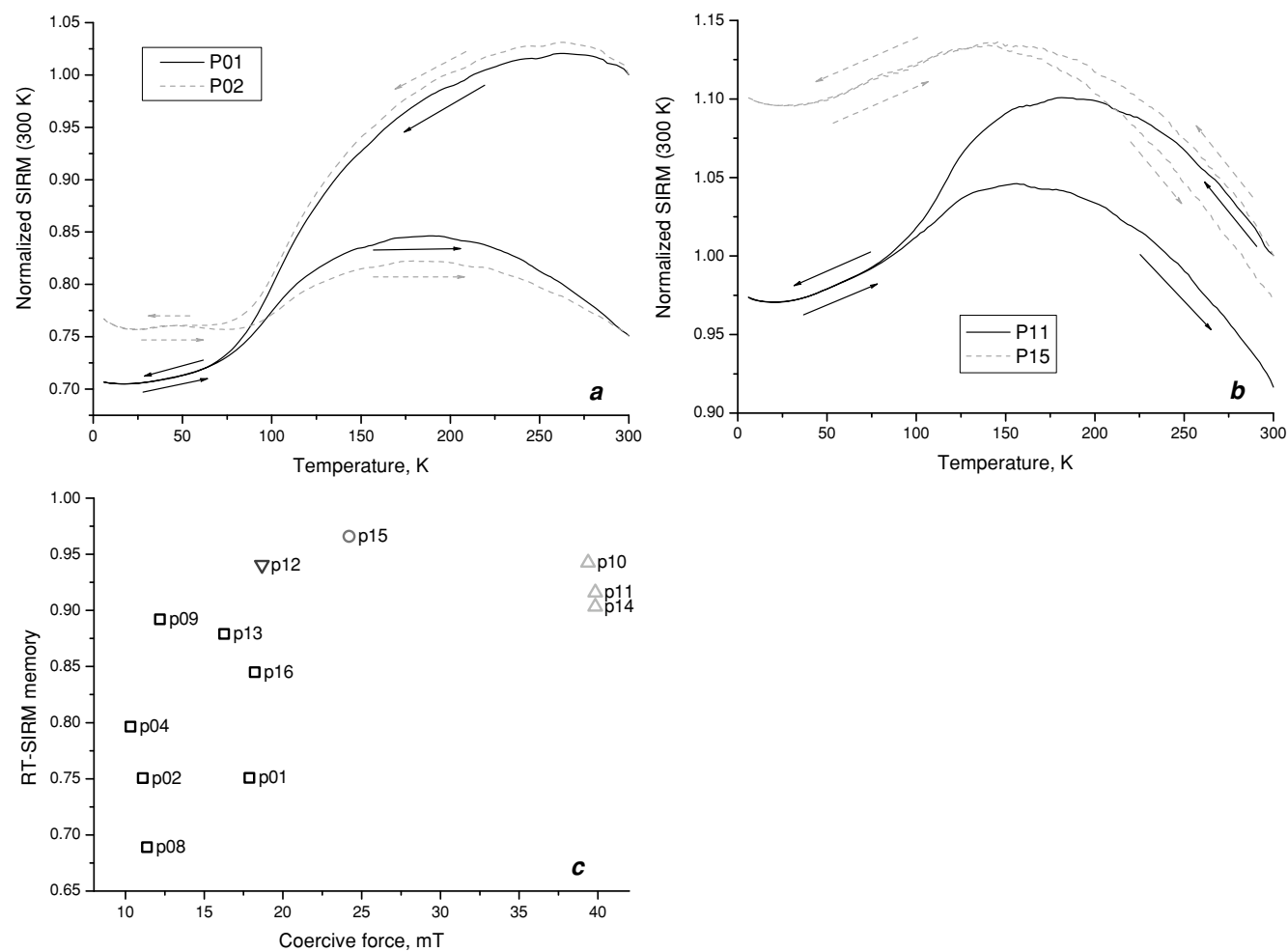

Fig. 5. Low-temperatures zero-field cycles of SIRM acquired at $300 \mathrm{~K}$ ((a), (b)) and dependence of RT-SIRM memory on coercivity (c).

others, most notably P01 and P10, the difference, although decreased, persists up to room temperature.

Typical examples of the behaviour of RT-SIRM during a cycle to $6 \mathrm{~K}$ in a zero magnetic field are shown in Fig. 5. In all cases, some remanence (from $<5 \%$ to $30 \%$ ) is lost in the end of the cycle. However, details differ from sample to sample. Again, two types of behaviour can be recognized. The first one (Fig. 5(a)) is characterized by cooling curves with broad maxima between 300 and $250 \mathrm{~K}$ where magnetization increases by $<5 \%$ from the $300-\mathrm{K}$ value. Below $250 \mathrm{~K}$ magnetization starts to decrease, reaching minimal values of about $0.7-0.8$ of RT-SIRM at $50-70 \mathrm{~K}$, de- 

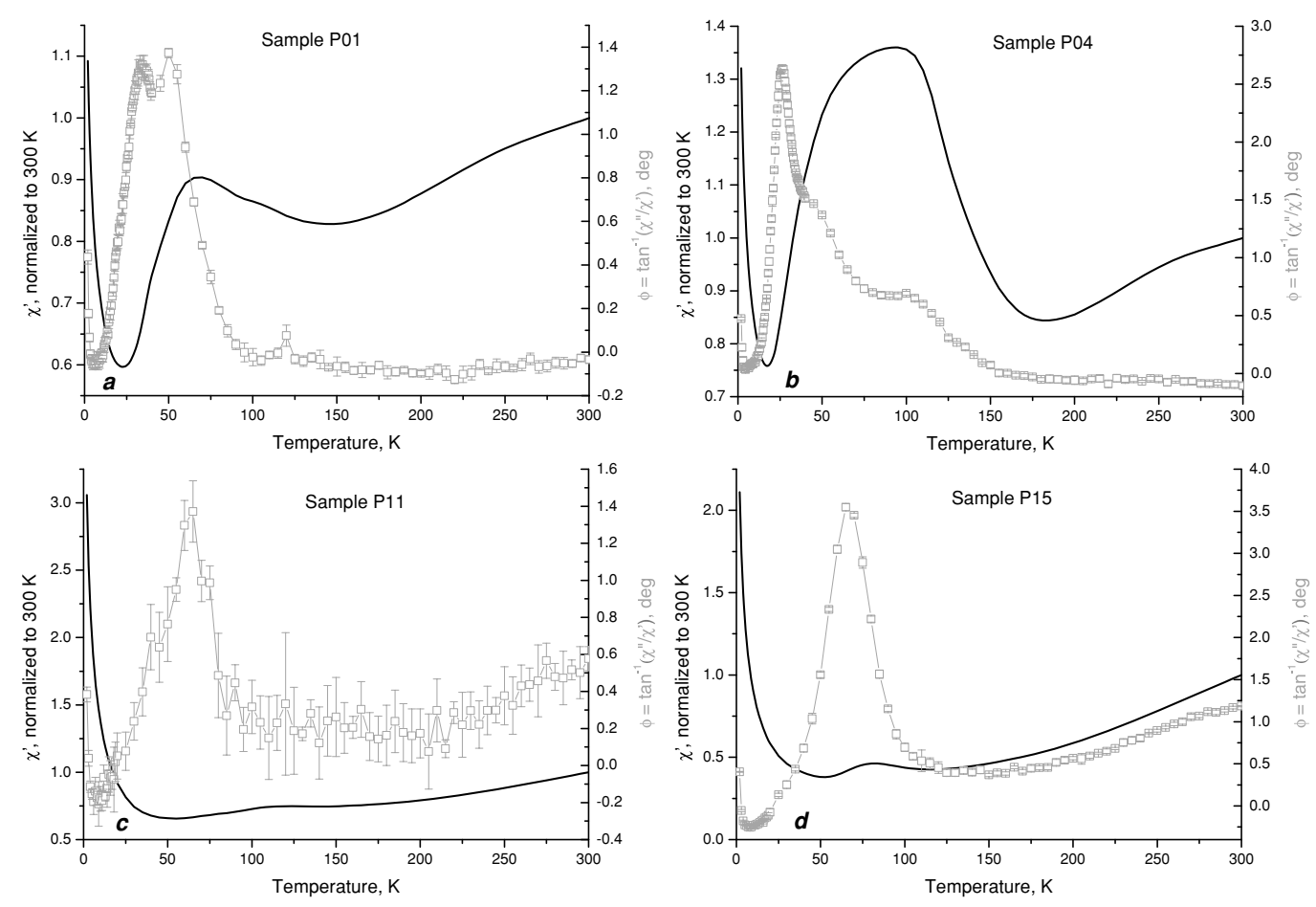

Fig. 6. Representative examples of temperature dependences of the in-phase (bold lines) and out-of-phase (squares) susceptibility.

pendent on a sample. At even lower temperatures, magnetization remains nearly constant or slightly increases. On consequent warming, magnetization follows cooling curve reversibly until the temperature at which minimum in the cooling curve occur is reached. Starting from this or a slightly higher temperature, a warming curve diverges from the cooling one. A local maximum is reached between 150 and $200 \mathrm{~K}$, followed by a gentle magnetization decrease. SIRM residue left after the complete cycle amounts to 70$80 \%$ of the initial SIRM value. The second type of behaviour (Fig. 5(b)) is characterized by a relatively larger reversibility between cooling and warming curves. The magnetization increase on cooling is quite significant, about $10 \%$ in most cases, and magnetization maxima are reached at lower temperatures (150-200 K) than in samples showing the first type of behaviour. By reaching the $6 \mathrm{~K}$ temperature, magnetization decreases at the most by $5 \%$ of the initial value, and in some samples, e.g. P15, magnetization actually increases. Warming curves are close replicas of the cooling ones; in particular, magnetization maxima are observed in the same temperature range as in the cooling curves. Finally, the overall loss of magnetization during the whole cycle is less than $10 \%$, much smaller than for samples showing the first type of behaviour.

\subsection{Low-field AC susceptibility}

Low-field AC susceptibility curves measured at cryogenic temperatures (Fig. 6) can be broadly classified into two types. The first (Fig. 6(a), (b)) is characterized, apart from the initial fast decrease below $20-25 \mathrm{~K}$, by a prominent peak in the in-phase susceptibility $\left(\chi^{\prime}\right)$, occurring at various temperatures between 40 and $120 \mathrm{~K}$. In samples showing this type of behaviour the out-of-phase susceptibility $\left(\chi^{\prime \prime}\right.$, expressed as phase angle $\left.\delta=\tan ^{-1}\left(\chi^{\prime \prime} / \chi^{\prime}\right)\right)$ also exhibits broad peaks in the same temperature range, often of a complex shape, and then disappears at temperatures $30-60 \mathrm{~K}$ above the $\chi^{\prime}$ peak. On the contrary, in samples belonging to the second group peaks in $\chi^{\prime \prime}$ and especially $\chi^{\prime}$ are much less pronounced, or even absent (Fig. 6(d)). Out-of-phase susceptibility, unlike that in the first group samples, is non-zero at all temperatures and, after peaking at $50-100 \mathrm{~K}$, tends to increase with increasing temperature just below $300 \mathrm{~K}$.

\subsection{Hysteresis properties}

In all our samples magnetic hysteresis properties change dramatically with decreasing temperature. At the lowest temperature, $10 \mathrm{~K}$, hysteresis loops cannot be saturated in the 1 Tesla field, as follows from the comparison of $\pm 1 \mathrm{~T}$ and $\pm 5 \mathrm{~T}$ loops (Fig. 7(a), (b)). We attempted to correct the latter for paramagnetism using a Brillouin function $B_{5 / 2}(H / T)$ to represent the paramagnetic fraction. Resulting hysteresis loops appear noticeably wasp-waisted (Fig. 7(c)). In the two samples used for comparison, the coercive force values determined from $\pm 1 \mathrm{~T}$ loops are lower by $20-30 \%$ than those determined from uncorrected $\pm 5 \mathrm{~T}$ loops. Correcting the latter for paramagnetism results in coercivities that are still higher by, respectively, 25\% (sample P01) and 90\% (sample P11). For other samples, the coercive force at $10 \mathrm{~K}$, as determined from uncorrected $\pm 1 \mathrm{~T}$ loops, is typically 40-60 mT and in some cases up to $80 \mathrm{mT}$. While it is demonstrably impossible to properly correct those loops for paramagnetism, the above example shows that these values may underestimate the true coercivity by up to a factor of two. It is worth noting that only a single sample showing very high coercivity at $10 \mathrm{~K}$ also shows an considerably elevated, as compared to others, coercive force at room temperature. Temperature dependences of coercive force (Fig. 8(a)) consist of an initial steeply falling segment extending in most cases to $40-70 \mathrm{~K}$, but sometimes to 120 

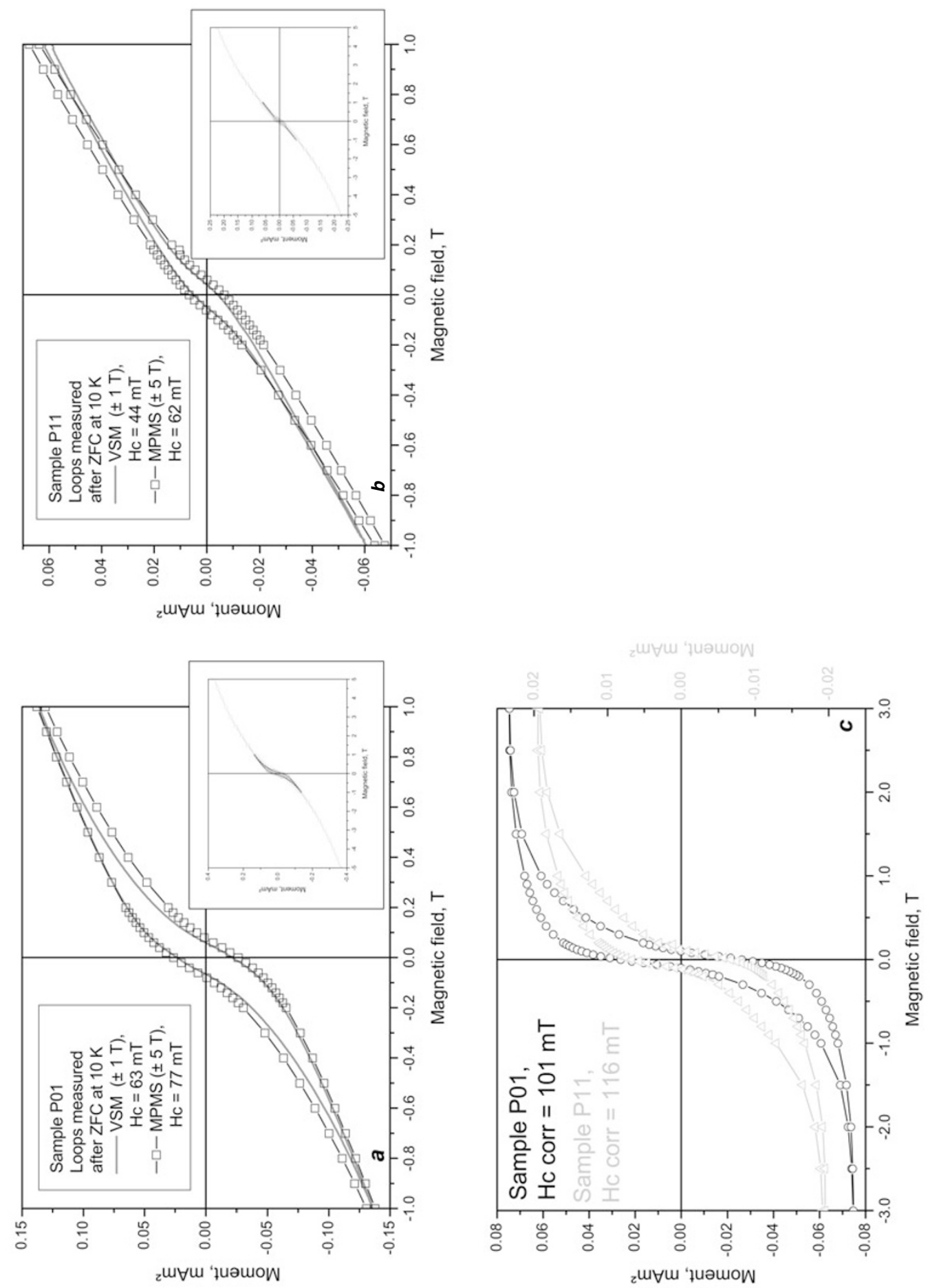

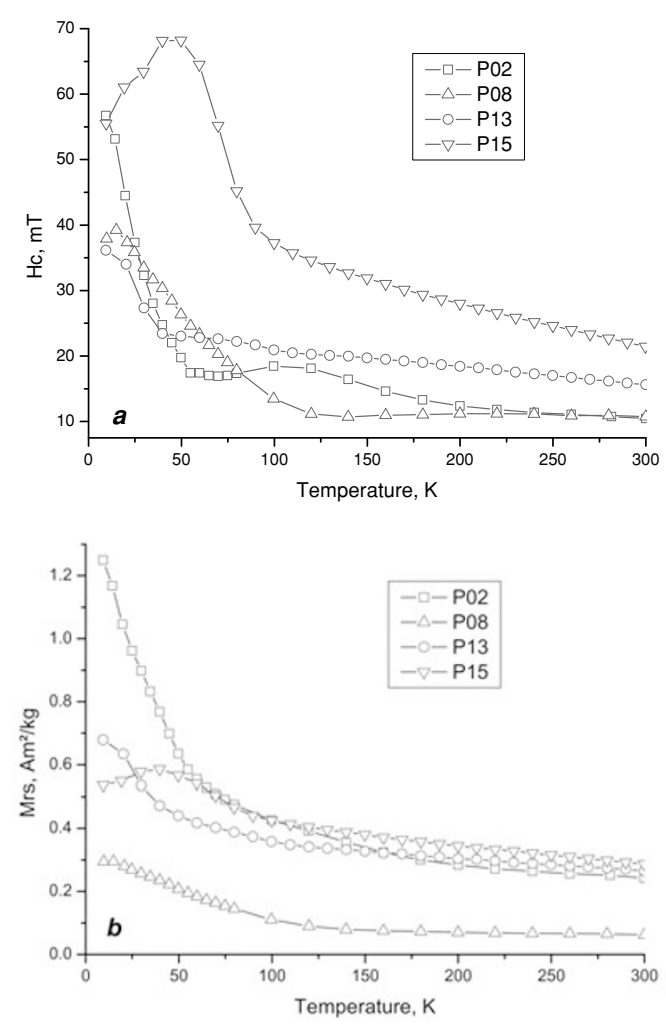

Fig. 8. Examples of temperature dependences of the coercive force (a) and saturation remanence (b), determined from \pm 1 Tesla hysteresis loops.

$150 \mathrm{~K}$, followed by a plateau or a gentle decrease. However, some samples (e.g. P15) show non-monotonous $H_{\mathrm{c}}$ temperature dependence, which is an artifact due to non-saturation of hysteresis loops in the 1 Tesla field. For this reason, meaningful $M_{\mathrm{s}}$ values and the respective $M_{\mathrm{rs}} / M_{\mathrm{s}}$ ratios also cannot be determined from hysteresis loops. We therefore consider temperature variation of $M_{\mathrm{rs}}$ instead (Fig. 8(b)). In most cases it is similar to that of the coercive force. However, initial steep decrease of $M_{\mathrm{rs}}$ is typically followed by a slower decrease, probably originating from the decrease of $M_{\mathrm{s}}$ with temperature.

\section{Discussion and Conclusions}

Low temperature magnetic measurements may be classified according to whether they carry information only on minerals contributing to the natural remanent magnetization of a rock or rather on all magnetic (sensu lato) minerals present. Of various experimental techniques used in the present work, only zero-field cycling of SIRM acquired at room temperature selectively affects mineral phases carrying NRM. It must be noted that this to be exactly correct, NRM carrying minerals must not exhibit interaction with phases ordering magnetically below room temperatures. In our case, the respective SIRM curves (Fig. 4) do not suggest that such interaction may be important, and therefore can be viewed as being entirely due to the phase(s) carrying NRM. Most of our samples have Curie temperatures in the range $430-540^{\circ} \mathrm{C}$. Bearing in mind their relatively low coercivity, the magnetic mineral present is likely titanomagnetite with compositions ranging from TM04 to TM20.
This composition range agrees with absence of the Verwey transition which disappears at about 3.5 atomic \% of Ti substitution (Kozłowski et al., 1996). As noted above (Section 3.2), curves of zero-field cycling of room temperature SIRM can be classified into two groups according to the degree of their irreversibility. The latter does not show any correlation with the Curie temperature, implying that the titanomagnetite composition is not a dominant factor here. However, RT-SIRM memory shows some positive correlation with the coercive force at room temperature (Fig. 5(c)), suggesting that different behaviour of the two groups could be caused by a variation in grain size. This is of course a feature familiar from studies on magnetite (Heider et al., 1992; Muxworthy and McClelland, 2000; Muxworthy et al., 2003), but in our samples rise in SIRM memory is additionally accompanied by a progressive evolution of curves' shape, generally not observed in magnetite.

All other experimental techniques used in this study yield an integrated response from all magnetic minerals in a rock, including those ordering below room temperature. This considerably complicates the interpretation of results. Since reference data for the candidate mineral phases are in short supply, only qualitative inferences on the magnetic mineralogy can be drawn. Let us consider first the magnetic susceptibility data. The $\chi-T$ curves show a rather variable shape, but neither of them resembles well-known curves for multidomain (Moskowitz et al., 1998; Muxworthy, 1999; Skumryev et al., 1999; Kosterov, 2003) or pseudo-single domain (Kosterov, 2003) magnetite. However, these curves can be classified into two groups according to their shape, and, furthermore, these groups overlap significantly with those identified in RT-SIRM cycling experiments (Table 1). More specifically, we use two classification criteria: (i) zero (within the experimental error) or non-zero value of $\chi^{\prime \prime}$ between 150-300 K, i.e. above $\chi^{\prime \prime}$ peak, and (ii) presence or absence of a peak in $\chi^{\prime}$. It is well known that intermediate titanomagnetites, unlike magnetite, show prominent field dependency of susceptibility in very small fields, on the order of $100 \mathrm{~A} / \mathrm{m}$ (Jackson et al., 1998). Non-zero values of $\chi^{\prime \prime}$, being caused with similar physical mechanisms, should be expected in them as well. Therefore samples showing substantially non-zero $\chi^{\prime \prime}$ between $150-300 \mathrm{~K}$ are probably dominated by titanomagnetite. Increase of $\chi^{\prime \prime}$ with temperature observed in many of the samples in this groups lends an additional support to this hypothesis. On the other hand, according to high-temperature $\chi-T$ curves, and to results of the paleomagnetic study of these rocks (Conte et al., 2004), titanomagnetites are present in all our samples. Therefore, in the samples showing near-zero $\chi^{\prime \prime}$ values in the $100-300 \mathrm{~K}$ interval (Fig. 6(a), (b)) susceptibility signal must be dominated by another mineral. Hemoilmenite with 80-90\% ilmenite content seems the most probable candidate. Indeed, at least some of our susceptibility curves resemble curves measured on synthetic samples of this composition (Ishikawa et al., 1985). Similar $\chi-T$ curves have been also reported for some Hawaiian basalts (Kontny et al., 2003; Yamamoto, 2006) where presence of (hemo) ilmenite was demonstrated by microscopic observations. On the other hand, Kosterov (2001) did not observe peaks attributable to (hemo) ilmenite is basalts from Karoo, Parana, 
and North Atlantic Large Igneous Provinces (LIPs), despite the fact that abundant exsolved titanomagnetite grains, where hemoilmenite should be present in lamellae (cf. Haggerty, 1976, 1991), were seen by SEM. It might be suggested therefore that only primary (hemo) ilmenites, and not those produced by deuteric oxidation, can be detected by low-temperature susceptibility measurements.

Bearing in mind the above classification according to low-temperature $\chi-T$ curves, consider now the meaning of characteristic features seen in the respective remanence curves and in hysteresis temperature dependences. In all four samples (P01, P02, P04, and P08), in which hemoilmenite appears to dominate LT susceptibility signal, LTSIRM curves consist of three distinct segments with slopes decreasing with increasing temperature. First break-inslope occurs between 30-50 K, and second around $200 \mathrm{~K}$. Temperature dependences of the coercive force show a similar trend. We propose that feature at $\sim 200 \mathrm{~K}$ is a manifestation of Néel temperature of hemoilmenite which would then contain about 20 mole $\%$ of hematite (Ishikawa et al., 1985). Break-in-slope at 30-50 K, on the other hand, is observed in all our samples, except one, and therefore is likely due to titanomagnetite.

Until now, very few studies have been specifically concerned with the magnetic behaviour of volcanic rocks at temperatures extending down to and below $4.2 \mathrm{~K}$. Kosterov (2001) have reported remanence and susceptibility data for basaltic samples from Karoo, Paraná, and North Atlantic large igneous provinces, and from hotspot-related Tahiti and Réunion volcanics. Kontny et al. (2003) have measured susceptibility and hysteresis loops as a function of temperature for Hawaiian basalts, also of hotspot origin. Additional low-temperature susceptibility data for Hawaiian volcanics have been reported by Yamamoto (2006). The present study thus extends the low-temperature magnetic measurements both in rock composition (andesites rather than basalts) and in tectonic setting (subduction-related volcanics). Even though the total number of studied samples for all three types of volcanics remain small, a certain progression from LIP basalts through hotspot ones towards subduction-related andesites seems to exist in magnetic properties. In LIP basalts, the primary NRM carrier is almost pure magnetite, always displaying the sharp Verwey transition. In contrast, in andesites titanomagnetites with compositions up to TM20 occur, as attested by the present study. Hotspot basalts appear to occupy an intermediate position.

In summary, low-temperature magnetic measurements can be used to identify both titanomagnetites and hemoilmenites in volcanic rocks. However, it must be stressed that both remanence and susceptibility data are essential to ensure that composition of both minerals is inferred correctly. Acquiring good reference data on their synthetic counterparts should improve the interpretation of measurements done on rocks, and must therefore given high priority in future studies.

Acknowledgments. Low-temperature measurements at Tokyo Institute of Technology and National Institute of Advanced Industrial Science and Technology, Tsukuba, have been carried out when AK was in receipt of Japan Society for the Promotion of
Science (JSPS) postdoctoral fellowship. We thank Dr. Toshitsugu Yamazaki (AIST) and Dr. Hideo Tsunakawa (Tokyo Tech) for providing access to their experimental facilities. Nobutatsu Mochizuki assisted in running the low-temperature VSM at Tokyo Tech, and Bertha Aguilar helped to run thermomagnetic measurements at UNAM. Final version of this manuscript has been prepared while AK held a JSPS Invitation Fellowship at Kochi University. AG acknowledges the financial support through projects Conacyt 54957 and UNAM DGAPA 102007. This paper benefited from the thoughtful review by Yongxin Pan.

\section{References}

Carrasco-Nuñez, G., L. Silva, H. Delgado-Granados, and J. UrrutiaFucugauchi, Geologia y paleomagnetismo del Popocatepetl, Mexico, DF, UNAM Publ. Ser. Inv. Inst. Geofis., no. 33, 1986.

Conte, G., J. Urrutia-Fucugauchi, A. Goguitchaichvili, A. M. SolerArechalde, O. Morton-Bermea, and A. Incoronato, Paleomagnetic study of lavas from the Popocatepetl volcanic region, Central Mexico, Int. Geol. Rev., 46, 210-225, 2004.

Dunlop, D. J., Theory and application of the Day plot $\left(M_{\mathrm{rs}} / M_{\mathrm{S}}\right.$ versus $\left.H_{\mathrm{cr}} / H_{\mathrm{c}}\right) 1$. Theoretical curves and tests using titanomagnetite data, $J$. Geophys. Res., 107, 10.1029/2001JB000486, 2002.

Haggerty, S. E., Opaque mineral oxides in terrestrial igneous rocks, in Oxide Minerals, edited by D. Rumble, Mineralogical Society of America Short Course Notes, 3, Hg101-Hg300, 1976.

Haggerty, S. E., Oxide textures-A mini-atlas, in Oxide Minerals: petrologic and magnetic significance, edited by D. L. Lindsley, Rev. Mineral., 25, 129-219, 1991.

Heider, F., D. J. Dunlop, and H. C. Soffel, Low-temperature and alternating field demagnetization of saturation remanence and thermoremanence in magnetite grains (0.037 mkm to $5 \mathrm{~mm})$, J. Geophys. Res., 97, 93719381, 1992.

Ishikawa, Y., N. Saito, M. Arai, Y. Watanabe, and H. Takei, A new oxide spin glass system of $(1-x) \mathrm{FeTiO}_{3}-x \mathrm{Fe}_{2} \mathrm{O}_{3}$. I. Magnetic properties, $J$. Phys. Soc. Jpn., 54, 312-325, 1985.

Jackson, M., B. M. Moskowitz, J. Rosenbaum, and C. Kissel, Field dependence of AC susceptibility in titanomagnetites, Earth Planet. Sci. Lett., 157, 129-139, 1998.

Kontny, A., C. Vahle, and H. de Wall, Characteristic magnetic behavior of subaerial and submarine lava units from the Hawaiian Scientific Drilling Project (HSDP-2), Geochem. Geophys. Geosyst., 4, 8703, doi: 10.1029/2002GC000304, 2003.

Kosterov, A., Magnetic properties of subaerial basalts at low temperatures, Earth Planets Space, 53, 883-892, 2001.

Kosterov, A., Low-temperature magnetization and AC susceptibility of magnetite: effect of thermomagnetic history, Geophys. J. Int., 154, 58$71,2003$.

Kosterov, A., Low-temperature magnetic properties, in Encyclopedia of Geomagnetism and Paleomagnetism, edited by D. Gubbins and E. Herrero-Bervera, Springer, Dortrecht, The Netherlands, 515-525, 2007.

Kozłowski, A., Z. Kąkol, D. Kim, R. Zaleski, and J. M. Honig, Heat capacity of $\mathrm{Fe}_{3-\alpha} \mathrm{M}_{\alpha} \mathrm{O}_{4}(\mathrm{M}=\mathrm{Zn}, \mathrm{Ti}, 0 \leq \alpha \leq 0.04)$, Phys. Rev. B, 54, 12093-12098, 1996.

Moskowitz, B. M., M. Jackson, and C. Kissel, Low-temperature magnetic behavior of titanomagnetites, Earth Planet. Sci. Lett., 157, 141-149, 1998.

Muxworthy, A. R., Low-temperature susceptibility and hysteresis of magnetite, Earth Planet. Sci. Lett., 169, 51-58, 1999.

Muxworthy, A. R. and E. McClelland, The causes of low-temperature demagnetization of remanence in multidomain magnetite, Geophys. J. Int., 140, 115-131, 2000.

Muxworthy, A. R., D. J. Dunlop, and Ö. Özdemir, Low-temperature cycling of isothermal and anhysteretic remanence: microcoercivity and magnetic memory, Earth Planet. Sci. Lett., 205, 173-184, 2003.

Radhakrishnamurty, C., S. D. Likhite, E. R. Deutsch, and G. S. Murthy, A comparison of the magnetic properties of synthetic titanomagnetites and basalts, Phys. Earth Planet. Inter., 26, 37-46, 1981.

Senanayake, W. E. and M. W. McElhinny, Hysteresis and susceptibility characteristics of magnetite and titanomagnetites: interpretation of results from basaltic rocks, Phys. Earth Planet. Inter., 26, 47-55, 1981.

Senanayake, W. E. and M. W. McElhinny, The effects of heating on lowtemperature hysteresis and susceptibility properties of basalts, Phys. Earth Planet. Inter., 30, 317-321, 1982.

Shau, Y.-H., M. Torii, C.-S. Horng, and D. R. Peacor, Subsolidus evolu- 
tion and alteration of titanomagnetite in ocean ridge basalts from Deep Sea Drilling Project/Ocean Drilling Program Hole 504B, Leg 83: Implications for the timing of magnetization, J. Geophys. Res., 105, 23635$23649,2000$.

Skumryev, V., H. J. Blythe, J. Cullen, and J. M. D. Coey, AC susceptibility of a magnetite crystal, J. Magn. Magn. Mater., 196-197, 515-517, 1999.

Thomas, N., An integrated rock magnetic approach to the selection or rejection of ancient basalt samples for palaeointensity experiments, Phys. Earth Planet. Inter, 75, 329-342, 1993.

Urrutia-Fucugauchi, J., C. Radhakrishnamurty, and J. F. W. Negendank,
Magnetic properties of a columnar basalt from central Mexico, Geophys. Res. Lett., 11, 832-835, 1984.

Yamamoto, Y., Possible TCRM acquisition of the Kilauea 1960 lava, Hawaii: failure of the Thellier paleointensity determination inferred from equilibrium temperature of the Fe-Ti oxide, Earth Planets Space, 58, 1033-1044, 2006.

A. Kosterov (e-mail: andrei_kosterov@mail.ru), G. Conte, A. Goguitchaichvili, and J. Urrutia-Fucugauchi 